\title{
A sutil diferença entre criar e educar - sobre a concepção freudiana da educação
}

\author{
Augusta Gerchmann
}

\begin{abstract}
Resumo: $\mathrm{O}$ trabalho aborda a relação entre educação e psicanálise. A manifestação da pulsão começa muito cedo; também a sexualidade é despertada precocemente, através da atividade de diferentes partes do corpo. Inicialmente caótica, a pulsão deve ser dominada, o que ocorre por meio da educação. O ser humano necessita aprender a dominar a pulsão para viver em sociedade e o meio mais eficaz se dá através da repressão, que poderá promover inibições e sintomas futuros. Para Freud, educar, governar e analisar são três profissões impossíveis. Quando os pais passam pela experiência de análise, poderão poupar os filhos de distorções semelhantes às por eles vividas.
\end{abstract}

Palavras-chave: Psicanálise. Educação. Sexualidade infantil. Pulsão. Repressão.

The subtle difference between raising and educating - On Freud's conception of education

\begin{abstract}
This paper discusses the relationship between education and psychoanalysis. The manifestation of the instinct, as well as sexuality, comes very early, throughout the activity of different parts of the body. Chaotic at the beginning, the instinct must be controlled, and this occurs through education. Human beings need to learn how to master their instinct in order to live in society, and the most effective way to achieve it is by repression, which can promote future inhibitions and symptoms. To Freud, educate, govern and analyze are three impossible professions. When parents go through the analysis experience, they might spare their children from the distortions they, the parents, have faced.
\end{abstract}

Keywords: Psychoanalysis. Education. Infantile sexuality. Instinct. Repression.

Assim, a educação tem de escolher seu caminho entre a Cila da não-interferência e o Caríbdis da frustração ${ }^{1}$ (FREUD, 1933 [1932], p. 138).

\section{Introdução}

O bebê humano nasce absolutamente desaparelhado para sobreviver sozinho, de modo que a passagem da vida intrauterina para o mundo pode representar o primeiro trauma pelo qual passa, o “trauma do nascimento", segundo Otto Rank (1924).

A manifestação da pulsão no bebê começa muito cedo, tendo origem na necessidade de saciar a fome e na respiração e para supri-las, precisará do auxílio de alguém empático a ele, despertandoatravés dessas necessidades básicas, sua vida psicossexual, que, assim, tem início com o próprio nascimento. São os pais, principalmente a mãe, quem, desde a chegada do bebê, exerceinfluência sobre ele, a partir

\footnotetext{
* Psicóloga, Psicanalista, Membro Titular e Didata da Sociedade Brasileira de Psicanálise de Porto Alegre. E-mail: augustagerchmann@hotmail.com

1 Tradução nossa.
}

\begin{tabular}{|l|l|l|l|l|l}
\hline APRENDER - Cad. de Filosofia e Psic. da Educação & Vitória da Conquista & Ano XI & n. 17 & p. 69-77 & jan./jun. 2017
\end{tabular}

DOI: $10.22481 /$ aprender.v0i17.3000

ISSN online: $2359-246 \mathrm{X}$ 
dos cuidados, uma primeira identificação, que é direta e imediata. Esse encontro inicial constitui o primeiro laço emocional que o bebê estabelece com seu semelhante, contribuindo para sua futura capacidade de amar.

A forma como o meio faz frente às suas necessidades, impulsos, desejos e dependência emocional deixa marcas, lembranças, que não poderão ser apagadas de seu corpo e de seu psiquismo, levando-o a retornar a períodos anteriores do desenvolvimento, através da regressão, para repetir as vivências e delas obter prazer. No entanto, quando a frustração se repete, poderá tornar-se uma compulsão a repetir, seja através do ato, seja através de ruminação do pensamento.

A vivência de desamparo inicial marca para sempre a condição humana, motivo pelo qual o indivíduo faz "qualquer coisa" para não repetir essa que representa a maior experiência de dor psíquica que o sujeito conhece. Assim, Freud, o fundador da psicanálise, depreende os danos que podem sofrer as crianças ao longo do desenvolvimento psicossexual.

\section{Entre Criar e Educar - Uma sutil diferença}

Durante mais de 40 anos, Freud descreveu a constituição do psiquismo, descobrindo que a criança possui uma sexualidade desde muito cedo, a qual participa e interfere na vida adulta. Criou, então, uma técnica a partir desses estudos que busca minimizar ou abolira dor psíquica, dor esta que se estrutura pela falta de subjetivação ou pela desadaptação à cultura. Deduziu, ainda, que, ao mesmo tempo que existe uma força que impele o sujeito para a vida, outra contrária o conduzà destruição.

Além disso, Freud concebe, através de observações e estudos afins, que a cultura, por sua vez, ao mesmo tempo que é necessária,também é causa de mal-estar.Depois deste profícuo trabalho, movido por sua persistência, conclui que "[...] analisar seria a terceira das profissões impossíveis em que se pode antecipar com certeza ainsuficiência de seus resultados. As outras duas, já há muito conhecidas, são o educar e o governar" (FREUD, 1937, p. 249, tradução nossa). Ao longo de seus escritos, igualmenteenfatiza a influência da educação no desenvolvimento infantil, principalmente na organização psíquica, indicando a importância da articulação entre educação e psicanálise.

A linguagem corrente não diferencia especificamente os vocábulos criar e educar, pois eles se originam do mesmo solo. No entanto, é na constituição do sujeito adulto que vamos nos deparar com os resultados de seu desenvolvimento infantil, mais precisamente com seus derivados, que se expressam através de inibições e sintomas, causa de sua dor psíquica e mal-estar no reduto da cultura.

Encontramos no dicionário Houaiss e Villar (2001) os seguintes significados para o vocábulo criar: conceber, tirar aparentemente do nada, dar existência a, formar, gerar, imaginar, inventar, produzir, causar, sustentar, cultivar, promover a educação de, instruir, educar-se sob certas condições, crescer em convívio com. Quanto ao vocábulo educar, encontramos no mesmo dicionário: dar a 
(alguém) todos os cuidados necessários ao pleno desenvolvimento de sua personalidade, transmitir saber a, instruir.

Para o propósito de nossa explanação, estes significados são suficientes, ao pensarmos que pode existir uma diferença "de base" entre criar uma criança e educá-la; no primeiro caso, podem contribuir aspectos mais inconscientes, que fazem parte da própria criação dos genitores e da subjetividade desses. No segundo caso, ou seja, na educação, participam atitudes formais e leis, que fazem parte das normas sociais na qual essa família está inserida, sobretudo sob a influência da cultura e da religião, nos seus aspectos éticos, estéticos e morais. O cruzamento entre o conceito e a práticapodemconstituir pontos cegosàs mensagens informais e formais que chegam ao aparelho psíquico, entrando em contradições pela soberania da pulsão.

Dessa forma, a psicanálise revela como a personalidade humana se desenvolve sob o impacto de duas forças contrapostas, as pulsões, por um lado, e as exigências sociais, por outro. Ainda que os aspectos constitucionais possam permanecer inalterados, sabemos que os fatores herdados e as vivências infantis contribuem sobremaneira para mitigar ou exacerbar o constitutivo. Assim, a criança precisará ser educada para conviver em sociedade, utilizando-se, a princípio, dos instrumentos psíquicos dos pais e cuidadores, que, por sua vez, trazem consigo sua própria história.

Freud, em O mal-estar na cultura (1930 [1929], p. 85), refere-se às três fontes de que provém o sofrimento: a fragilidade do corpo, a força da natureza e a insuficiência das normas que regulam os vínculos recíprocos entre os homens na família, no estado e na sociedade. Como apontamos anteriormente, a pulsão do ser humano começa muito cedo e sua ação seria caótica se não houvesse lei, já que ela anseia satisfazer-se através de sua descarga e ficaria à mercê de arbitrariedade se submetida somente às leis da natureza, sem interferência da cultura e, portanto, da ordem.

Isso posto, somos convocados a pensar em como as tramas entre os vínculos atuais na cultura vigente repercutem na singularidade do indivíduo, ao passo que não raro assistimos a filhos desamparados e despreparados para conviver com seu semelhante, para amar e para trabalhar, ameaçados de sofrimento desde as três fontes anteriormente citadas.

\section{Sobre o Desenvolvimento Infantil}

O artigo intitulado Três ensaios para uma teoria da sexualidade (FREUD, 1905) representa um marco na obra de Freud e uma virada no pensamento da época, tendo causado muitas dissidências entre os adeptos da psicanálise, em função, sobretudo, da moral e dos pudores da Viena do século XIX. De qualquer forma, os seguidores do legado de Freud buscam ampliar sua compreensãodo desenvolvimento da organização sexual infantil, contribuindo para a educação das crianças e para a 
busca de um sentido possível a muitas patologias psíquicas que tiveram sua origem neste período do desenvolvimento.

Como refere Freud no segundo dos ensaios mencionados, $A$ sexualidade infantil, "Um estudo profundo das manifestações sexuais na infância nos revelaria provavelmente os traços essenciais da pulsão sexual, desvendaria sua evolução e nos mostraria que está composta por diversas fontes” (1905, p. 157, tradução nossa). Atribui à amnésia infantil a razão de os adultos combaterem esse achado, que seria consequência de sua própria educação, já que o esquecimento natural, próprio da infância, encobre as vivências dos primeiros anos de todo ser humano.

Para Freud (1905), a vida sexual do ser humano tem início com o nascimento, acrescentando, ao discutir A história de uma neurose infantil (1918 [1914]), a existência de esquemas filogeneticamente herdados que seriam precipitados da história da cultura humana e o Complexo de Édipo, neste contexto, o exemplo mais conhecido dessa classe. Para ele, as "categorias filosóficas, procuram a colocação das impressões vitais" (FREUD, 1918 [1914], p. 108, tradução nossa) e, onde as vivências não se adequam ao esquema hereditário, são remodeladas na fantasia.

Durante os primeiros quatro anos da infância, podem ser observados diretamente os desdobramentos deste percurso, antes que a criança internalize uma censura, como decorrência da instauração do superego. No estudo sobre a vida de Leonardo da Vinci (1910), Freud assevera que "Nos primeiros três ou quatro anos de vida se fixam impressões e se abrem formas de reação ao mundo externo cujo significado não poderá mais ser diminuído por nenhuma vivência posterior" (FREUD, 1910, p. 85, tradução nossa). Abordando a investigação sexual infantil, mais especificamente quanto à pulsão de saber, relaciona-a com uma forma sublimada do desejo de apoderamento por um lado e pelo outro com a energia da pulsão escopofílica, afirmando que é a própria sexualidade que desperta na criança a pulsão de saber sobre a sexualidade.

Freud aprofunda estas ideias quando publica o atendimento indireto ao pequeno Hans através do pai da criança e na análise que realiza da personalidade de Leonardo da Vinci (1910). Nesses artigos, reconhece que, em ambos os casos, o anseio que as crianças precocemente têm por decifrar enigmas, pela sede de saber, dizem respeitoà investigação sexual infantil. As pesquisas infantis giram em torno da origem dos bebês, da vida sexual dos pais, da diferença anatômica entre os sexos e de sua própria origem, acrescentadas as fantasias que, com frequência, confundem-se com vivências infantis, modificadas e falseadas. A maneira como sua curiosidade é satisfeita designaamiúde os meandros de sua vida sexual futura, que pode ser substituída por capacidade extrema de sublimação em detrimento da capacidade de amar.

Assim, fica claro que as relações dos filhos com os pais estão longe de ser inocentes e, ao longo dos seus primeiros cinco anos de vida, a criança passa por uma intensa e turbulenta vida amorosa acompanhada de desejos e sensações que ela vai gradualmente descobrindo, à medida que perpassa as diferentes fases do desenvolvimento sexual infantil. 
Passado esse período da sexualidade infantil, caracterizado pelo polimorfismo perverso, quando as pulsões parciais se unem sob o primado genital, com o reconhecimento das diferenças sexuais, as crianças ingressamno período da latência, aparecendo, então, entraves no caminho da pulsão sexual, como "diques" - asco, vergonha e exigências estéticas e morais. Para Freud, a educação permanece "por inteiro, na esfera da competência que lhe foi assinalada quando se limita a seguir o que foi prefixado organicamente, imprimindo-lhe uma forma mais ordenada e profunda" (FREUD, 1905, p. 161, tradução nossa).

Ao assinalar as Rupturas do período de latência, refere-se aos educadores dizendo que eles:

[...] à medida que prestam alguma atenção à sexualidade infantil, se conduzem como se compartilhassem nossas opiniões acerca da formação dos poderes de defesas morais a expensas da sexualidade, e como se soubessem que a prática sexual faz da criança ineducável; em efeito, perseguem como 'vícios' todas as exteriorizações sexuais da criança, ainda que sem conseguir muito contra elas (FREUD, 1905, p. 161, tradução nossa).

E segue: “[...] nós temos fundamento para interessarmo-nos por esses fenômenos temidos pela educação, pois esperamos que eles nos esclareçam sobre a conformação originária da pulsão sexual" (FREUD, 1905, p. 162, tradução nossa).

Ao escrever sobre $A$ moral sexual "cultural" e o nervosismo moderno, Freud propõe que seria tarefa da educação restringir, desde o período do autoerotismo à relação objetal, os prazeres incontroláveis suscitados pela pulsão sexual que não fossem aproveitáveis no futuro, relacionando ao trabalho de reprimir os elementos chamados perversos da excitação sexual (FREUD, 1908, p. 169).

Para o autor, a influência da educação e das exigências sociais, a repressão das pulsões perversas fracassa, mas, como elas foram inibidas no seu status nascendi, já não se manifestam como tais. Elas se exteriorizam de outras formas, ainda que permaneçam nocivas para o sujeito, identificando no nervosismo, especificamente como psiconeuroses, o fenômeno substitutivo. Daí Freud descrever que a neurose é o negativo da perversão, uma vez que o destino da pulsão - repressão - pode tornar-se transformação no seu oposto e/ou retorno contra a própria pessoa. Mesmo o destino da sublimação pode tornar-se patológico quando excessivo. Aduz, ainda, como a experiência ensina para a maioria dos humanos que existe um limite além do qual sua constituição não pode obedecer às exigências culturais (FREUD, 1908, p. 171). A educação severa, que não tolera nenhuma atividade sexual precocemente despertada, convoca o poder repressor que arrasta consigo um conflito, despertando os motivos necessários para a causação de doenças psíquicas que persistirão por toda a vida (FREUD, 1908, p. 180).

No mesmo artigo, Freud ainda atribui à educação a causa da inferioridade intelectual das mulheres, desencorajadas em sua curiosidade e inibidas de realizarem investigações sexuais enquanto 
crianças, incorrendo no prejuízo de sua capacidade de pensar. Somente a partir das primeiras décadas do século XX, o mundo ocidental passou a questionar o poder social, político e econômico até então monopolizado pelos homens, mas ainda hoje encontramos culturas que mantém as mulheres no lugar a elas atribuído no passado.

Quando Freud descreve as semelhanças do processo cultural com o desenvolvimento libidinal do sujeito, refere ter a sublimação um papel substantivo na vida cultural, impondo a renúncia das pulsões àqueles que desejam viver em harmonia com as exigências essenciais da cultura. Em outras palavras, a liberdade individual que gozou a criança ao longo da primeira infância deve ser limitada, as pulsões dominadas através do trabalho da educação restringindo a satisfação plena em favor do desenvolvimento cultural. No fundo, para o fundador da psicanálise, o ser humano não quer abdicar da felicidade, mas esta é relativizada pelo temor de perda do amor e pela angústia da vivência do desamparo que já experimentou.

$\mathrm{Na}$ conferência de 1933, Esclarecimentos, aplicações, orientações, Freud trata especificamente da aplicação da psicanálise na educação, inclusive defendendo seus benefíciospara a geração seguinte, oferecendo esperanças de futuro. Neste contexto, pensamos que poderia, assim, haver mal-entendidos entre criar e educar, na medida em que há diferenças entre o que é transmitido conscientemente e o que se passa inconscientemente.

O autor prossegue afirmando que o estudo do adulto neurótico leva impreterivelmente a sua infância, período que contém os germes do florescimento precoce da sexualidade e deixa estímulos decisivos para a vida sexual adulta (FREUD, 1933 [1932], p. 136). Sendo assim, somentemediante a repressão o Ego pode defender-se dessas tempestades afetivas da primeira infância, adquirindo, entretanto, as predisposições para as enfermidades e distúrbios psíquicos posteriores. Dessa maneira, a criança necessita apropriar-se, num breve lapso de tempo, dos resultados de uma evolução que se estendeu ao longo de milênios: o domínio das pulsões e a adaptação social. Somente uma parte seria alcançada nos desdobramentos da evolução infantil naturalmente, devendo aí a educação interferir.

Neste artigo, Freud é categórico ao atribuir como tarefa da educação, ensinara dominar as pulsões da criança, que não pode seguir seus impulsos sem limitação. Portanto, cabe à educação inibir, proibir e sufocar as pulsões não aceitáveis. Por outro lado, como um paradoxo, a psicanálise demonstra que justamente a supressão da pulsão pode ser causa do adoecimento psíquico. Sendo assim, a influência educacionalé medida pelas disposições constitucionais que devem levar em conta os aspectos e configurações singulares de cada criança e de seu entorno. Uma ampliação do espectro educacionalintervém na influência dos traumas infantis acidentais, um dos aspectos que contribuem na etiologia da neurose (FREUD, 1933 [1932], p. 138).

Através do estudo de Leonardo da Vinci, Freud observa que a enérgica repressão sexual pode levar a uma inibição permanente, tanto na vida sexual quanto na capacidade intelectual, tornando-se ainda mais limitada quando a criança é exposta ao poder que a religião tem de inibir, ainda mais quando 
a educação nela se apoia. Se as inibições neuróticas permanecem na vida adulta, poderão, em alguns casos, não interferir na capacidade intelectual, mas ser por ela auxiliada e,nesse sentido, a capacidade intelectual contorna a repressão sexual que fora suprimida, retornando como sexualização do pensamento e trazendo consigo prazer e angústia similares aos processos sexuais propriamente ditos.

Freud conclui que a maneira mais adequada do adulto se preparar para a função de educador seria através de um consistente treino em psicanálise. Hoje, nossa compreensão é mais fortemente sustentada pelo que acompanhamos na clínica, mas já naquela época era avistada a importância de uma análise pessoal para os pais, auxiliando-os a lidar com seus próprios complexos e processos psíquicos. A compreensão analítica é omeio possível de não se repetir os erros do passado, poupando os filhos do que eles, pais, não foram poupados.

O pai da Psicanálise esclarece, no artigo publicado postumamente, o Esboço de Psicanálise (1940), referindo-se às influências do funcionamento psíquico dos pais e de gerações anteriores, que o Id e o Superego, apesar de sua diversidade fundamental, possuem uma característica em comum: ambos representam as influências do passado; o Id as do passado herdado, e o Superego, essencialmente, as do passado assumido por outros. O Ego, por sua vez, é determinado, essencialmente, pelas vivências próprias do indivíduo - pelo atual e acidental (FREUD, 1940 [1938]).

O superego, que, de chegada, expressa-se como Ego Ideal, termina de constituir-se como herdeiro do Complexo de Édipo, quando a criança abandona o desejo de possuir o genitor do sexo oposto e de rivalizar com o genitor do mesmo sexo. Torna-se, assim, o Ideal do Ego, esperando SER como os genitores e TER aquilo que os mesmos possuem, baseando-se também nos valores por eles transmitidos. Para algumas pessoas, a distância entre o que é capaz de ser e o seu ideal torna-se fonte de baixa ou ausência de autoestima, sustentada pela carência afetiva e pelo narcisismo dos pais, que esperariam que a geração posterior prosseguisse a sua história.

\section{Conclusão}

Os estudos de Freud acerca do primeiro ano de vida mostraram a importância da relação mãefilho-ambiente no que se refere à aquisição da confiança básica por parte da criança, suporte para ela desenvolver-se com liberdade e criatividade. Um suporte confiável auxilia a criança a enfrentar as frustrações inevitáveis e, por vezes, necessárias, especialmente em se tratando de experimentar diferentes e antagônicos sentimentos com relação às primeiras pessoas de sua relação e poder fantasiar ao longo de sua existência.

Apesar dos esforços dos pais, são vários os motivos que geram frustrações para a criança, no que diz respeito às pulsões sexuais, compreendidas nas diferentes partes do corpo que se sobressaem em cada fase do desenvolvimento psicossexual da libido. A cada mudança dessas fases, a criança deixa 
para trás, ou deveria deixar, a fase precedente, como um meio de seguir em frente. No caso de ocorrer fixação em uma fase anterior, a ela poderá retornar em momento de crise, promovido pela regressão a que o psiquismo é suscetível.

O indivíduo não adoece somente por consequência de proibições externas, mas, sobretudo, pela combinação dessas com fatores internos que o predispõem em maior ou menor grau, somado à internalização das relações de reciprocidade que se oferecem como modelo, que irão constituir seu psiquismo. A descoberta freudiana dessas interações trouxe importante contribuição para a educação infantil e para a constituição da subjetividade do adulto.

Para os pais, por sua vez, primeiros educadores, cabe uma tarefa complexa e de grandes exigências, entre elas ser o mediador privilegiado entre a criança e o mundo, tarefa esta que segue exercida pelos professores ao longo do período escolar.Como referimos no início deste artigo, pensamos haver uma sutil diferença entre criar uma criança e educá-la, lembrando que educar é uma profissão impossível como governar e analisar.

Ainda que pais e educadores busquem na psicanálise uma fonte esclarecedora, sabemos que o exercício dessas orientações, no cotidiano, nem sempre são viáveis; sendo muitos os fatores externos e internos que se combinam para causar sofrimento psíquico. Nos avatares da vida infantil, mesmo com a melhor das intenções, pode não ser possível evitar as surpresas que o mundo desconhecido prega na vida de uma criança despreparada para proteger-se.

$\mathrm{Na}$ luta entre Eros (pulsão de vida) e Tanatos (pulsão de destruição), o processo cultural é a modificação que o processo vital experimenta pela influência de uma tarefa convocada por Eros e incitada por Ananké - a necessidade objetiva, que consiste na união de seres humanos isolados em uma comunidade ligada libidinalmente. Ao considerar o nexo entre o processo cultural da humanidade e o processo de desenvolvimento ou educação do indivíduo, não se hesitará emafirmarque possuem semelhanças quanto à sua natureza, além de se relacionarem a um mesmo processo, envolvendo objetos de categorias diferentes.

Concluímos assim, que é para poder conviver em sociedade e preservar o amor do outro que o sujeito busca dominar sua pulsão, para não ser por ela dominado. Esta, talvez, venha a ser a principal tarefa da educação.

\section{Referências}

FREUD, S. (1905). Três ensaios da teoria sexual. In: Obras completas. Buenos Aires: Amorrortu, 1989. v. 7, p. 157-162.

. (1908). A moral sexual "cultural" e o nervosismo moderno. In: . Obras completas.

Buenos Aires: Amorrortu, 1989. v. 9. 
. (1909). Análise da fobia de um menino de cinco anos. In:

Obras completas. Buenos

Aires: Amorrortu, 1989. v. 10, p. 84-117.

. (1910). Uma recordação de infância de Leonardo da Vinci. In: Obras completas. Buenos

Aires: Amorrortu, 1989. v. 11.

(1920). Mais além do princípio do prazer. In: Obras completas. Buenos Aires:

Amorrortu, 1989. v. 18, p. 18-59.

. (1926 [1925]). Inibição, sintoma e angústia. In: Obras completas. Buenos Aires:

Amorrortu, 1989. v. 20, p. 97-135.

. (1930 [1929]). O mal-estar na cultura. In: 1989. v. 21, p. 130-140.

. Obras completas. Buenos Aires: Amorrortu,

. (1933 [1932]). Novas conferências introdutórias sobre psicanálise. In: Obras completas.

Buenos Aires: Amorrortu, 1989. v. 22, p. 126-145.

. (1940 [1938]). Esquema de Psicanálise. In: Obras completas. Buenos Aires: Amorrortu, 1989. v. 23, p. 145.

- (1937). Análise terminável e interminável. In: Obras completas. Buenos Aires:

Amorrortu, 1989. v. 23, p. 249.

HOUAISS, A.; VILLAR, Mauro de S. Dicionário Honaiss da Lingua Portuguesa. Rio de Janeiro: Objetiva, 2001. p. 868-1101.

RANK, Otto. O mito do nascimento do herói. São Paulo: Edipro, 2015. Original publicado em 1924. 